\title{
The present-day decadal solar cycle modulation of Earth's radiative forcing via charged $\mathrm{H}_{2} \mathrm{SO}_{4} / \mathrm{H}_{2} \mathrm{O}$ aerosol nucleation
}

\author{
J. Kazil, ${ }^{1,2}$ K. Zhang, ${ }^{3,4}$ P. Stier, ${ }^{5}$ J. Feichter, ${ }^{3}$ U. Lohmann, ${ }^{6}$ and K. O’Brien ${ }^{7}$ \\ Received 18 October 2011; revised 19 December 2011; accepted 26 December 2011; published 24 January 2012.
}

[1] The decadal solar cycle modulation of Earth's radiative forcing via ionization of the atmosphere by galactic cosmic rays, aerosol formation from the gas phase, and the response of clouds to aerosol is quantified for the first time with a climate model that represents and couples the relevant processes. Simulations are conducted for solar maximum and minimum conditions, with present-day anthropogenic aerosol and aerosol precursor gas emissions, and contemporary large-scale meteorology. The solar cycle signal appears in atmospheric ionization, aerosol formation from the gas phase, aerosol concentrations, aerosol optical depth, and in cloud properties, and is most pronounced at mid- and high latitudes. The resulting solar cycle modulation of Earth's radiative forcing exhibits a distinct hemispheric asymmetry, with peak values of $-0.14 \mathrm{~W} \mathrm{~m}^{-2}$ in the southern and $-0.06 \mathrm{~W} \mathrm{~m}^{-2}$ in the northern mid-latitudes. Globally and annually averaged, the solar cycle modulation of Earth's radiative forcing, arising from the increase in atmospheric ionization by galactic cosmic rays from solar maximum to minimum, via charged nucleation of aerosol, the direct aerosol effect, and the cloud albedo effect, amounts to $-0.05 \mathrm{~W} \mathrm{~m}^{-2}$. A limited relevance of this variation for the Earth's atmosphere and climate can be inferred, given that Earth's radiative forcing changes by $-0.24 \mathrm{~W} \mathrm{~m}^{-2}$ from solar maximum to minimum because of a decrease in total solar irradiance. Citation: Kazil, J., K. Zhang, P. Stier, J. Feichter, U. Lohmann, and K. O'Brien (2012), The present-day decadal solar cycle modulation of Earth's radiative forcing via charged $\mathrm{H}_{2} \mathrm{SO}_{4} /$ $\mathrm{H}_{2} \mathrm{O}$ aerosol nucleation, Geophys. Res. Lett., 39, L02805, doi:10.1029/2011GL050058.

\section{Introduction}

[2] The role of solar variability for Earth's climate, and its possible ramifications for global climate change have been a subject of ongoing research in the 20th and early 21 st century [Gray et al., 2010]. The topic gained increased attention after Svensmark and Friis-Christensen [1997] reported a correlation of global cloud cover with the intensity of

\footnotetext{
${ }^{1}$ Cooperative Institute for Research in Environmental Sciences, University of Colorado at Boulder, Boulder, Colorado, USA.

${ }^{2}$ Chemical Sciences Division, Earth System Research Laboratory, NOAA, Boulder, Colorado, USA.

${ }^{3}$ Max Planck Institute for Meteorology, Hamburg, Germany.

${ }^{4}$ Pacific Northwest National Laboratory, Richland, Washington, USA.

${ }^{5}$ Atmospheric, Oceanic and Planetary Physics, Department of Physics, University of Oxford, Oxford, UK.

${ }^{6}$ Institute for Atmospheric and Climate Science, ETH Zurich, Zurich, Switzerland.

${ }^{7}$ Department of Physics and Astronomy, Northern Arizona University, Flagstaff, Arizona, USA.

Copyright 2012 by the American Geophysical Union. 0094-8276/12/2011GL050058
}

galactic cosmic rays (GCRs) based on satellite observations, and Marsh and Svensmark [2000] estimated a resulting variation in Earth's radiative forcing by $1.2 \mathrm{~W} \mathrm{~m}^{-2}$ over the decadal solar cycle. The mechanism by which solar variability could affect Earth's clouds has been originally proposed, with a note of skepticism, by Dickinson [1975]: Polar molecules with a low saturation vapor pressure, such as sulfuric acid, could attach to ions produced in the atmosphere by GCRs, and contribute to the atmospheric aerosol population [see, e.g., Kazil et al., 2008] - the substrate on which cloud drops form. GCR ionization of the atmosphere is anti-correlated with the decadal solar cycle [Forbush, 1954; Neher and Forbush, 1958], as the Sun's magnetic field and the solar wind, which wax and wane with solar activity, shield the heliosphere from GCRs. The solar cycle signal could therefore appear in the cloud drop number and in Earth's radiative forcing via the Twomey [1974] and Albrecht [1989] effects.

[3] Earlier model studies, without directly simulating the link between GCR ionization and cloud properties, have placed upper bounds on a possible role of decadal solar variability for Earth's radiative forcing via aerosol nucleation from GCR-produced ions: Kazil et al. [2006] found that the variation in GCR ionization over the decadal solar cycle does not entail a response in aerosol production and cloud cover via the Albrecht [1989] effect that would explain the variations in global cloud cover reported by Svensmark and Friis-Christensen [1997], and estimated that the change in Earth's radiative forcing from solar maximum to minimum is at most $-0.22 \mathrm{~W} \mathrm{~m}^{-2}$ in industrial times. Pierce and Adams [2009] found that changes in aerosol concentrations from changes in cosmic rays over a decadal solar cycle are two orders of magnitude too small to account for the observed changes in cloud properties, and concluded that the effect of aerosol formation from GCR-produced ions is too small to play a significant role in climate change.

[4] A comprehensive review of research on solar effects on climate, with pertinent references, has been given by Gray et al. [2010]. In the present work, the decadal solar cycle modulation of Earth's radiative forcing, via ionization of the atmosphere by GCRs, aerosol formation from the gas phase, and the response of clouds to aerosol is quantified for the first time with a climate model that represents and couples the relevant processes.

\section{Model and Simulations}

[5] The aerosol-climate model ECHAM5-HAM [Stier et al., 2005] is used, which describes aerosol and cloud processes in the troposphere and their radiative effects through scattering and absorption of radiation. Aerosol and clouds are coupled in ECHAM5-HAM [Lohmann et al., 


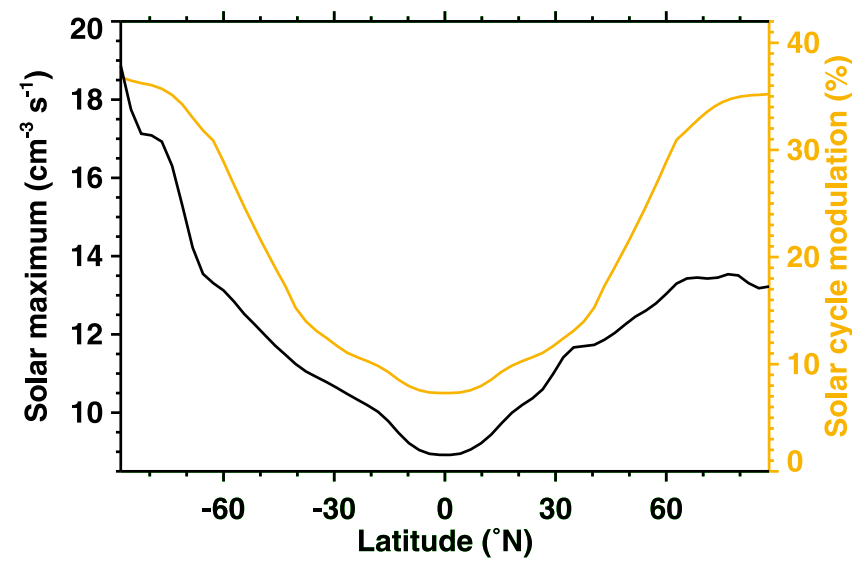

Figure 1. GCR ionization rate in solar maximum conditions (black), and the solar cycle modulation (change from solar maximum to minimum) thereof (beige), after temporal, vertical, and zonal averaging of the model results.

2007]: cloud drop number and size, and cloud albedo respond to changes in aerosol concentrations via the Twomey [1974] effect, thereby altering the amount of solar radiation reflected back to space. Aerosol concentrations in the model respond to changes in aerosol nucleation from the gas phase, which is in part driven by GCR ionization of the atmosphere [Kazil et al., 2010]. Cloud cover is represented with an empirical cloud cover scheme [Sundqvist et al., 1989], which depends only on relative humidity (RH), but not directly on changes in aerosol concentrations via the Albrecht [1989] effect. A causal effect of aerosol on cloud cover [Albrecht, 1989] and its quantification are controversial [Stevens and Feingold, 2009; Quaas et al., 2009; Koren et al., 2010]. Satellites observe a strong correlation between aerosol optical depth and cloud cover [e.g., Quaas et al., 2010], but a dependence of both quantities on wind speed [Engström and Ekman, 2010] and swelling of aerosol particles in humidified air near clouds [Quaas et al., 2010] appear to be the dominant cause.

[6] Ionization of the atmosphere by GCRs is described based on the analytical theory of O'Brien [2005]. The GCRproduced ions drive aerosol formation from the gas phase via charged nucleation of sulfuric acid $\left(\mathrm{H}_{2} \mathrm{SO}_{4}\right)$ and water $\left(\mathrm{H}_{2} \mathrm{O}\right)$ in the model. Charged and neutral nucleation of $\mathrm{H}_{2} \mathrm{SO}_{4}$ and $\mathrm{H}_{2} \mathrm{O}$ depend on temperature, $\mathrm{RH}$, concentration of $\mathrm{H}_{2} \mathrm{SO}_{4}$ and its condensation sink onto pre-existing aerosol, and on the ionization rate, and the resulting aerosol formation rate is implemented with a look-up table [Kazil et al., 2010] that was calculated with the semi-analytical method of Kazil and Lovejoy [2007]. The resulting aerosol formation rates have been compared with chamber experiments by Kirkby et al. [2011]. Nucleation via cluster activation [Kulmala et al., 2006] is implemented in the model in the forested boundary layer with the parametrization of Sihto et al. [2006].

[7] Hoose et al. [2009] demonstrated that a lower limit for the cloud drop number in aerosol-climate models may significantly increase the response of cloud albedo to aerosol. To avoid an undue limitation of the cloud albedo response to changes in aerosol in the course of the solar cycle, this limit was reduced to $10 \mathrm{~cm}^{-3}$ in this work (from the default of $40 \mathrm{~cm}^{-3}$ ), which renders cloud albedo very sensitive to changes in aerosol concentrations: the resulting reduction of (short-wave) radiative forcing from pre-industrial to present-day conditions due to anthropogenic aerosol and aerosol precursor gas emissions amounts to a high value of $-2.2 \mathrm{~W} \mathrm{~m}^{-2}$ [cf. Forster et al., 2007; Hoose et al., 2009].

[8] Simulations are conducted for solar maximum $\left(\mathcal{S}_{\max }^{2000}\right)$ and minimum $\left(\mathcal{S}_{\min }^{2000}\right)$ activity conditions, corresponding to low (high) atmospheric ionization by GCRs, respectively. Anthropogenic aerosol and aerosol precursor gas emissions for the year 2000 are used, and are described, together with emissions of natural aerosol and aerosol precursor gases in Stier et al. [2005]. The simulations are nudged towards ERA-40 reanalysis data [Simmons and Gibson, 2000] in order to reproduce the large-scale meteorology of the year 2000, and monthly mean AMIP II sea surface temperatures and sea ice cover [Taylor et al., 2000] are used. Each simulation covers ten iterations of the year 2000, initialized with the final state of the preceding iteration. The first iteration is initialized with the final state of a three months spin-up period. The model domain is resolved with 19 vertical levels between the surface and $10 \mathrm{hPa}$ (L19), a horizontal grid with a mean resolution of $2.8^{\circ}$ (T42), and a time step of $1800 \mathrm{~s}$.

\section{Results}

[9] We define the absolute and relative decadal solar cycle modulation of a model quantity $Q$ as $Q\left(\mathcal{S}_{\min }^{2000}\right)-Q\left(\mathcal{S}_{\max }^{2000}\right)$ and $\left[Q\left(\mathcal{S}_{\min }^{2000}\right)-Q\left(\mathcal{S}_{\max }^{2000}\right)\right] / Q\left(\mathcal{S}_{\max }^{2000}\right)$, respectively. The modulation is calculated after the model quantities have been averaged temporally over the ten annual iterations of the simulations, vertically, weighted with air mass, if the quantity depends on altitude, and zonally. The averaging aims at removing random variability in the results (model noise), in order to isolate differences between the simulations arising from different GCR ionization levels. However, this approach may not sufficiently suppress model noise in quantities with a weak solar cycle signal. An area-weighted, box-shaped low-pass filter that stretches over nine latitude points is used to further reduce model noise. The filter becomes less effective with increasing proximity to the poles, where its length in latitude direction is reduced. Higher variability in the solar cycle modulation near the poles than at other latitudes may indicate the inability of the filter to suppress the local noise.

[10] Figure 1 shows the GCR ionization rate in solar maximum conditions and its solar cycle modulation as functions of latitude. The ionization rate is lowest near the equator and increases towards the poles owing to the orientation of the Earth's magnetic field: Near the equator, where the Earth's magnetic field lines align with the surface, only the most energetic among the charged particles that make up GCRs have sufficiently large gyroradii to penetrate deep into the atmosphere. Towards the poles, however, as the Earth's magnetic field lines steepen relative to the surface, less energetic GCRs can travel deep into the atmosphere, resulting in a higher ionization. The change in the GCR ionization rate from solar maximum to minimum exhibits a similar latitude dependence, and rises from $\sim 7 \%$ near the equator to $\sim 36 \%$ near the poles. The larger increase near the poles is due to a stronger solar cycle modulation at lower energies of the cosmic ray spectrum [Shea and Smart, 2004]. 

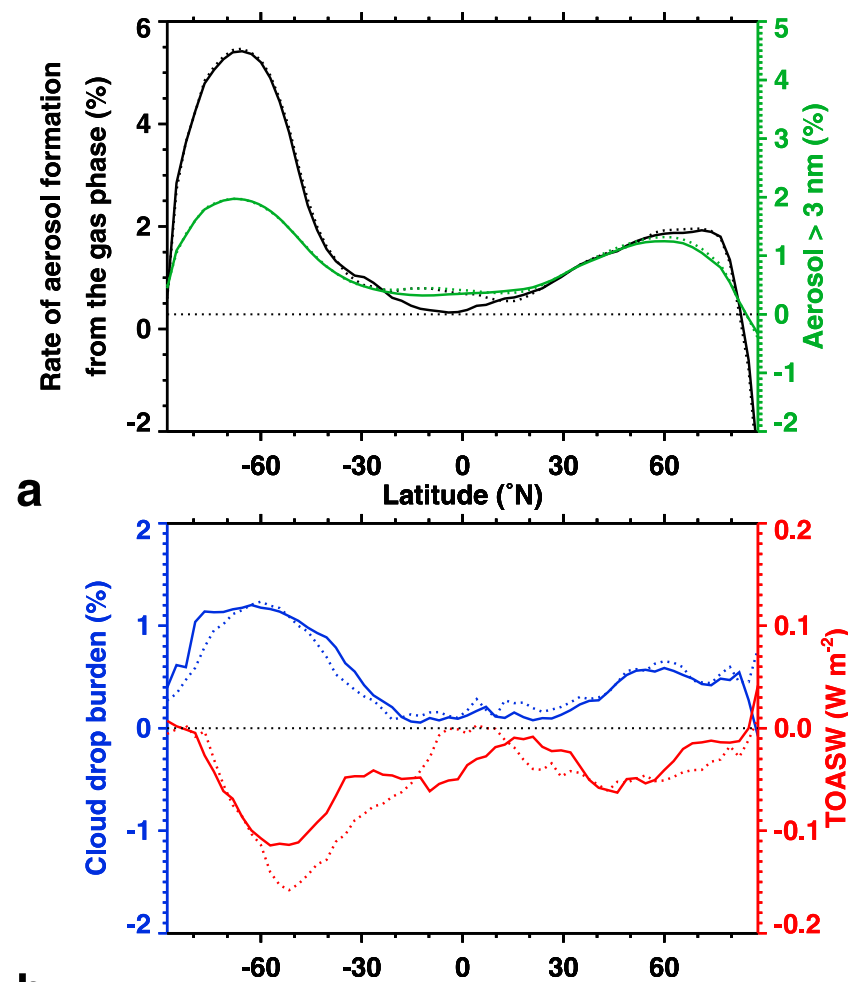

b

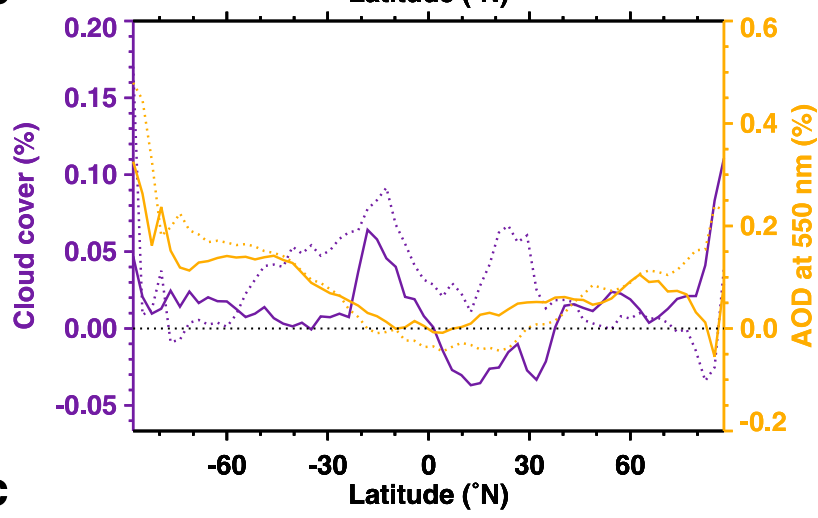

Figure 2. Solar cycle modulation (change from solar maximum to minimum) of the (a) formation rate of aerosol particle number from the gas phase (black) and of the concentration of aerosol particles with dry diameter $>3 \mathrm{~nm}$ (green), (b) cloud drop burden (blue) and net top-of-the-atmosphere short-wave radiation (TOASW) (red), and (c) cloud cover (purple) and aerosol optical depth (AOD) (gold). Solid (dotted) lines represent results from simulations with the default (increased) resolution look-up table for $\mathrm{H}_{2} \mathrm{SO}_{4} / \mathrm{H}_{2} \mathrm{O}$ nucleation, respectively. The solar cycle modulation was calculated after temporal, vertical, and zonal averaging of the model results, and after smoothing with a box-shaped, areaweighted low-pass filter that stretches over nine latitude points. Results without filtering are shown in Figure S4 in the auxiliary material.

[11] Figure 2 shows the solar cycle modulation of selected quantities, calculated from averaged and filtered model results. Figure $2 \mathrm{a}$ shows the solar cycle modulation of the particle formation rate $\mathcal{J}$ from all nucleation processes in the model, and of the concentration $\mathcal{N}_{3 \mathrm{~nm}}$ of aerosol particles with dry diameter $>3 \mathrm{~nm} . \mathcal{N}_{3 \mathrm{~nm}}$ is, for all practical purposes, a close representation of the total aerosol concentration, as 3 $\mathrm{nm}$ is a widely used lower diameter cutoff in aerosol concentration measurements. The modulation of $\mathcal{J}$ exhibits low values in the tropics, maxima near the polar circles, and negative values in the Arctic. This latitudinal distribution arises from the solar cycle modulation of the ionization rate (Figure 1), and from the latitudinal variation in temperature (Figure $\mathrm{S} 1$ in the auxiliary material), $\mathrm{H}_{2} \mathrm{SO}_{4}$ concentration (Figure $\mathrm{S} 2$ in the auxiliary material) and $\mathrm{H}_{2} \mathrm{SO}_{4}$ condensation sink (Figure $\mathrm{S} 3$ in the auxiliary material), which, together with $\mathrm{RH}$, control charged $\mathrm{H}_{2} \mathrm{SO}_{4} / \mathrm{H}_{2} \mathrm{O}$ nucleation [Kazil et al., 2010]: A low modulation of ionization and warm temperatures in the tropical lower troposphere, which hinder charged $\mathrm{H}_{2} \mathrm{SO}_{4} / \mathrm{H}_{2} \mathrm{O}$ nucleation, result in a low modulation of $\mathcal{J}{ }^{1}$ With distance to the tropics, the modulation of ionization increases and temperatures decrease, promoting charged $\mathrm{H}_{2} \mathrm{SO}_{4} / \mathrm{H}_{2} \mathrm{O}$ nucleation and its modulation by the solar cycle. This alliance does not extend to the polar regions, however, where high ionization rates meet low $\mathrm{H}_{2} \mathrm{SO}_{4}$ concentrations. In these conditions, loss of subcritical charged clusters due to recombination is fast, and cluster growth due to $\mathrm{H}_{2} \mathrm{SO}_{4}$ condensation slow - more so at the warmer northern hemisphere temperatures - resulting in a low or negative response of the charged $\mathrm{H}_{2} \mathrm{SO}_{4} / \mathrm{H}_{2} \mathrm{O}$ nucleation rate to an increase in ionization [Kazil and Lovejoy, 2004]. The solar cycle modulation of $\mathcal{N}_{3 \mathrm{~nm}}$ follows that of $\mathcal{J}$, with a smaller magnitude, owing to coagulation loss of particles from charged $\mathrm{H}_{2} \mathrm{SO}_{4} / \mathrm{H}_{2} \mathrm{O}$ nucleation, and owing to the contribution of other nucleation mechanisms and surface-emitted aerosol to $\mathcal{N}_{3 \mathrm{~nm}}$.

[12] Figure 2b shows the solar cycle modulation of the cloud drop burden (CDB, vertically integrated cloud drop number concentration) and of net top-of-the-atmosphere short-wave radiation (TOASW). The modulation of CDB follows that of $\mathcal{N}_{3 \mathrm{~nm}}$, but has a more pronounced hemispheric asymmetry. We explain the higher modulation in the southern hemisphere with its higher coverage by pristine ocean clouds, which are more susceptible to aerosol. The modulation of TOASW mirrors that of CDB, with extrema in each hemisphere. These extrema are collocated, and can therefore be phenomenologically associated with the corresponding peaks in the modulation of CDB [Twomey, 1974]. The simulations give a weak solar cycle modulation of cloud cover (Figure 2c). This weak modulation may arise from an underestimation of aerosol-cloud cover effects, as cloud cover responds only to RH in the simulations. The modulation of AOD (Figure 2c) features low values in the tropics, and increases towards higher latitudes. Very high or low AOD modulation values near the poles are likely the result of insufficiently suppressed model noise.

[13] To assess the role of resolution of the look-up table for $\mathrm{H}_{2} \mathrm{SO}_{4} / \mathrm{H}_{2} \mathrm{O}$ nucleation [Kazil et al., 2010], simulations with the default look-up table resolution, and with a resolution increased by a factor of 1.5 in every variable of the look-up table (v.s.) are compared in Figure 2. The modulation of $\mathcal{J}$ and $\mathcal{N}_{3 \mathrm{~nm}}$ responds little to the increase in look-up table resolution (Figure 2a). Counterintuitively, a much stronger response appears in the modulation of $\mathrm{CDB}$ and TOASW (Figure 2b), and cloud cover and AOD (Figure 2c). Cloud cover, which depends only on RH, would be expected

${ }^{1}$ Auxiliary materials are available in the HTML. doi:10.1029/ 2011 GL050058 
Table 1. Solar Cycle Modulation (Change From Solar Maximum to Minimum), Calculated After Global and Annual Averaging of the Model Results ${ }^{\mathrm{a}}$

\begin{tabular}{ccc}
\hline Nucleation Look-up Table Resolution: & Default & Increased \\
\hline Aerosol > $3 \mathrm{~nm}(\%)$ & 0.71 & 0.74 \\
Cloud drop burden (\%) & 0.39 & 0.40 \\
Cloud cover (\%) & 0.0075 & 0.0318 \\
Aerosol optical depth (\%) & 0.050 & 0.026 \\
TOASW (W m ${ }^{-2}$ ) & -0.047 & -0.054 \\
\hline
\end{tabular}

${ }^{\mathrm{a}}$ Values were obtained from simulations with the default resolution of the look-up table for neutral and charged $\mathrm{H}_{2} \mathrm{SO}_{4} / \mathrm{H}_{2} \mathrm{O}$ nucleation, and with an increased resolution (see text). TOASW refers to the net short-wave radiation at the top-of-the-atmosphere.

to be least sensitive to the nucleation look-up table resolution. It follows that the modulation in CDB, TOASW, cloud cover, and AOD is affected more by random differences (model noise) between the solar maximum and minimum simulations than by the discrete nature of the representation of $\mathrm{H}_{2} \mathrm{SO}_{4} / \mathrm{H}_{2} \mathrm{O}$ nucleation.

[14] Table 1 gives the solar cycle modulation calculated after global and annual averaging of the model results. Since a model setup was used in which cloud albedo is very sensitive to aerosol variations, and as ionization sources which do not vary with the solar cycle, such as radioactive decay of radon, are not accounted for in this work, these solar cycle modulation values should be considered upper limit estimates. On average, the solar cycle modulation of $\mathcal{N}_{3 \mathrm{~nm}}$ is $0.73 \%$, and propagates with $0.40 \%$ into the CDB. Cloud cover, being sensitive only to $\mathrm{RH}$ in this work, exhibits a very small solar cycle modulation, as does AOD. The globally averaged solar cycle modulation of TOASW is about $-0.05 \mathrm{~W} \mathrm{~m}^{-2}$, roughly one fifth of the $-0.24 \mathrm{~W} \mathrm{~m}^{-2}$ change of TOASW due to the reduction by $0.1 \%$ of total solar irradiance from solar maximum to minimum [Lean and Rind, 1998].

\section{Summary and Conclusions}

[15] The decadal solar cycle modulation of Earth's radiative forcing via ionization of the atmosphere by galactic cosmic rays, aerosol formation from the gas phase, and the response of clouds to aerosol is quantified with a climate model that represents and couples the relevant processes. Present-day anthropogenic aerosol and aerosol precursor gas emissions, and contemporary large-scale meteorology were used. In the simulations, the solar cycle modulates atmospheric ionization by galactic cosmic rays, aerosol formation from the gas phase, aerosol concentrations, aerosol optical depth, cloud properties, and Earth's radiative forcing. The solar cycle modulation of Earth's radiative forcing exhibits a distinct hemispheric asymmetry, with peak values of $-0.14 \mathrm{~W} \mathrm{~m}^{-2}$ in the southern and $-0.06 \mathrm{~W} \mathrm{~m}^{-2}$ in the northern mid-latitudes. This asymmetry can be explained with the higher coverage of pristine ocean clouds in the south, which are more susceptible to aerosol. A weak solar cycle modulation of cloud cover, which in this work responds only to relative humidity, is obtained. A weak solar cycle modulation is also found in the aerosol optical depth. Globally and annually averaged, the solar cycle modulation of Earth's radiative forcing, arising from the increase in atmospheric ionization from solar maximum to minimum, via charged nucleation of aerosol, the direct aerosol effect, and the cloud albedo effect amounts to $-0.05 \mathrm{~W} \mathrm{~m}^{-2}$. A limited relevance of this variation for the Earth's atmosphere and climate can be inferred, given that Earth's radiative forcing changes by $-0.24 \mathrm{~W} \mathrm{~m}^{-2}$ from solar maximum to minimum because of a decrease in total solar irradiance.

[16] Acknowledgments. This work was supported by NOAA's Climate Goal (NOAA OAR Climate Program Office grant NA08OAR4310566) and the European Integrated Project on Aerosol-Cloud-Climate and Air Quality Interactions (EUCAARI) 036833-2. All simulations were performed at the German Climate Computing Center (Deutsches Klimarechenzentrum GmbH, DKRZ). PS was supported by the Natural Environment Research Council project AEROS [NE/G006148/1]. The first author gratefully acknowledges the NCAR Advanced Study Program, the High Altitude Observatory, the United States National Research Council, the Max Planck Institute for Meteorology, and the NOAA ESRL Chemical Sciences Division.

[17] The Editor thanks two anonymous reviewers for their assistance in evaluating this paper.

\section{References}

Albrecht, B. A. (1989), Aerosols, cloud microphysics and fractional cloudiness, Science, 245, 1227-1230, doi:10.1126/science.245.4923.1227.

Dickinson, R. E. (1975), Solar variability and the lower atmosphere, Bull. Am. Meteorol. Soc., 56(12), 1240-1248, doi:10.1175/1520-0477(1975) $056<1240$ :SVATLA $>2.0 . \mathrm{CO} ; 2$.

Engström, A., and A. M. L. Ekman (2010), Impact of meteorological factors on the correlation between aerosol optical depth and cloud fraction, Geophys. Res. Lett., 37, L18814, doi:10.1029/2010GL044361.

Forbush, S. E. (1954), Worldwide cosmic ray variations, 1937-1952, J. Geophys. Res., 59, 525-542, doi:10.1029/JZ059i004p00525.

Forster, P., et al. (2007), Changes in atmospheric constituents and in radiative forcing, in Climate Change 2007: The Physical Science Basis. Contribution of Working Group I to the Fourth Assessment Report of the Intergovernmental Panel on Climate Change, edited by S. Solomon et al., pp. 129-234, Cambridge Univ. Press, Cambridge, U. K.

Gray, L. J., et al. (2010), Solar influences on climate, Rev. Geophys., 48, RG4001, doi:10.1029/2009RG000282.

Hoose, C., J. E. Kristjánsson, T. Iversen, A. Kirkevåg, Ø. Seland, and A. Gettelman (2009), Constraining cloud droplet number concentration in GCMs suppresses the aerosol indirect effect, Geophys. Res. Lett., 36, L12807, doi:10.1029/2009GL038568.

Kazil, J., and E. R. Lovejoy (2004), Tropospheric ionization and aerosol production: A model study, J. Geophys. Res., 109, D19206, doi:10.1029/ 2004JD004852.

Kazil, J., and E. R. Lovejoy (2007), A semi-analytical method for calculating rates of new sulfate aerosol formation from the gas phase, Atmos. Chem. Phys., 7, 3447-3459, doi:10.5194/acp-7-3447-2007.

Kazil, J., E. R. Lovejoy, M. C. Barth, and K. O’Brien (2006), Aerosol nucleation over oceans and the role of galactic cosmic rays, Atmos. Chem. Phys., 6, 4905-4924, doi:10.5194/acpd-6-5543-2006.

Kazil, J., R. G. Harrison, and E. R. Lovejoy (2008), Tropospheric new particle formation and the role of ions, Space Sci. Rev., 137, 241-255, doi:10.1007/s11214-008-9388-2.

Kazil, J., et al. (2010), Aerosol nucleation and its role for clouds and Earth's radiative forcing in the aerosol-climate model ECHAM5-HAM, Atmos. Chem. Phys., 10, 10,733-10,752, doi:10.5194/acp-10-10733-2010.

Kirkby, J., et al. (2011), Role of sulphuric acid, ammonia and galactic cosmic rays in atmospheric aerosol nucleation, Nature, 476, 429-433, doi:10.1038/nature103431.

Koren, I., G. Feingold, and L. A. Remer (2010), The invigoration of deep convective clouds over the Atlantic: Aerosol effect, meteorology or retrieval artifact?, Atmos. Chem. Phys., 10, 8855-8872, doi:10.5194/ acp-10-8855-2010.

Kulmala, M., K. E. J. Lehtinen, and A. Laaksonen (2006), Cluster activation theory as an explanation of the linear dependence between formation rate of $3 \mathrm{~nm}$ particles and sulphuric acid concentration, Atmos. Chem. Phys., 6, 787-793, doi:10.5194/acp-6-787-2006.

Lean, J., and D. Rind (1998), Climate forcing by changing solar radiation, J. Clim., 11, 3069-3094, doi:10.1175/1520-0442(1998)011<3069: CFBCSR $>2.0 . \mathrm{CO} ; 2$.

Lohmann, U., P. Stier, C. Hoose, S. Ferrachat, S. Kloster, E. Roeckner, and J. Zhang (2007), Cloud microphysics and aerosol indirect effects in the global climate model ECHAM5-HAM, Atmos. Chem. Phys., 7, 3425-3446, doi:10.5194/acp-7-3425-2007.

Marsh, N., and H. Svensmark (2000), Cosmic rays, clouds, and climate, Space Sci. Rev., 94, 215-230, doi:10.1023/A:1026723423896. 
Neher, H. V., and S. E. Forbush (1958), Correlation of cosmic ray-intensity and solar activity, Phys. Rev. Lett., 1(5), 173-174, doi:10.1103/ PhysRevLett.1.173.

O'Brien, K. (2005), The theory of cosmic-ray and high-energy solar-particle transport in the atmosphere, in The Natural Radiation Environment VII, edited by J. P. McLaughlin, E. S. Simopoulos, and F. Steinhäusler, pp. 29-44, Elsevier, Amsterdam, doi:10.1016/S1569-4860(04)07004-4.

Pierce, J. R., and P. J. Adams (2009), Can cosmic rays affect cloud condensation nuclei by altering new particle formation rates?, Geophys. Res. Lett., 36, L09820, doi:10.1029/2009GL037946.

Quaas, J., et al. (2009), Aerosol indirect effects - General circulation model intercomparison and evaluation with satellite data, Atmos. Chem. Phys., 9, 8697-8717, doi:10.5194/acp-9-8697-2009.

Quaas, J., B. Stevens, P. Stier, and U. Lohmann (2010), Interpreting the cloud cover-Aerosol optical depth relationship found in satellite data using a general circulation model, Atmos. Chem. Phys., 10, 6129-6135, doi:10.5194/acp-10-6129-2010.

Shea, M. A., and D. F. Smart (2004), Preliminary study of cosmic rays, geomagnetic field changes and possible climate changes, Adv. Space Res., 34, 420-425, doi:10.1016/j.asr.2004.02.008.

Sihto, S.-L., et al. (2006), Atmospheric sulphuric acid and aerosol formation: Implications from atmospheric measurements for nucleation and early growth mechanisms, Atmos. Chem. Phys., 6, 4079-4091, doi:10.5194/ acp-6-4079-2006.

Simmons, A. J., and J. K. Gibson (2000), The ERA-40 project plan, ERA-40 Proj. Rep. Ser. 1, Eur. Cent. for Medium-Range Weather Forecasts, Reading, U. K.

Stevens, B., and G. Feingold (2009), Untangling aerosol effects on clouds and precipitation in a buffered system, Nature, 461, 607-613, doi: 10.1038 /nature 08281 .

Stier, P., et al. (2005), The aerosol-climate model ECHAM5-HAM, Atmos. Chem. Phys., 5, 1125-1156, doi:10.5194/acp-5-1125-2005.
Sundqvist, H., E. Berge, and J. E. Kristjánsson (1989), Condensation and cloud parameterization studies with a mesoscale numerical weather prediction model, Mon. Weather Rev., 117, 1641-1657, doi:10.1175/15200493(1989)117<1641:CACPSW $>2.0 . C O ; 2$.

Svensmark, H., and E. Friis-Christensen (1997), Variation of cosmic ray flux and global cloud coverage-A missing link in solar-climate relationships, J. Atmos. Terr. Phys., 59, 1225-1232, doi:10.1016/S13646826(97)00001-1.

Taylor, K. E., D. Williamson, and F. Zwiers (2000), The sea surface temperature and sea-ice concentration boundary conditions for AMIP II simulations, PCMDI Rep. 60, Program for Clim. Model Diagn. and Intercomp., Lawrence Livermore Natl. Lab., Livermore, Calif.

Twomey, S. (1974), Pollution and the planetary albedo, Atmos. Environ., 8(12), 1251-1256, doi:10.1016/0004-6981(74)90004-3.

J. Feichter, Max Planck Institute for Meteorology, Bundesstr. 53, D-20146 Hamburg, Germany. (johann.feichter@zmaw.de)

J. Kazil, Chemical Sciences Division, Earth System Research Laboratory, NOAA, 325 Broadway, Boulder, CO 80305, USA. (jan.kazil@noaa.gov)

U. Lohmann, Institute for Atmospheric and Climate Science, ETH Zurich, Universitätstr. 16, CH-8092 Zürich, Switzerland. (ulrike.lohmann@env. ethz.ch)

K. O'Brien, Department of Physics and Astronomy, Northern Arizona University, NAU Box 6010, Flagstaff, AZ 86011, USA. (keran. o'brien@nau.edu)

P. Stier, Atmospheric, Oceanic and Planetary Physics, Department of Physics, University of Oxford, Parks Road, Oxford OX1 3PU, UK. (philip.stier@physics.ox.ac.uk)

K. Zhang, Pacific Northwest National Laboratory, 902 Battelle Blvd., Richland, WA 99352, USA. (kai.zhang@pnnl.gov) 